https://helda.helsinki.fi

\title{
Propagating ice front induces gas bursts and ultrasonic acoustic emissions from freezing xylem
}

\section{Lintunen, Anna}

2020-02

Lintunen , A , Losso , A , Aalto , J , Chan , T , Hölttä , T \& Mayr , S 2020 , ' Propagating ice front induces gas bursts and ultrasonic acoustic emissions from freezing xylem ', Tree Physiology , vol. 40 , no. 2 , pp. 170-182 . https://doi.org/10.1093/treephys/tpz123

http://hdl.handle.net/10138/323510

https://doi.org/10.1093/treephys/tpz123

acceptedVersion

Downloaded from Helda, University of Helsinki institutional repository.

This is an electronic reprint of the original article.

This reprint may differ from the original in pagination and typographic detail.

Please cite the original version. 
1 Title: Propagating ice front induces gas bursts and ultrasonic acoustic emissions from

2 freezing xylem

3

4 Authors: Anna Lintunen ${ }^{1,2}$, Adriano Losso ${ }^{3}$, Juho Aalto ${ }^{1}$, Tommy Chan ${ }^{1}$, Teemu Hölttä ${ }^{2}$, and 5 Stefan $\mathrm{Mayr}^{3}$

6

7 Contact info:

8 Austria

20

${ }^{1}$ Institute for Atmospheric and Earth System Research / Physics, Faculty of Science, P.O. Box 64, FI-00014 University of Helsinki, Finland

${ }^{2}$ Institute for Atmospheric and Earth System Research / Forest Sciences, Faculty of Agriculture and Forestry, P.O. Box 27, FI-00014 University of Helsinki, Finland

${ }^{3}$ Department of Botany, University of Innsbruck, Sternwartestrasse 15, A-6020 Innsbruck,

Correspondence: Anna Lintunen

Email: anna.lintunen@helsinki.fi

Running title: Freezing-induced gas bursts and acoustic emissions

Keywords: acoustic emissions; bark permeability; freeze-thaw cycles; effective diffusion coefficient of $\mathrm{CO}_{2}$; respiration; winter embolism 


\section{Abstract}

Ice formation and propagation in the xylem of plants is a complex process. During freezing of xylem sap, gases dissolved in liquid sap are forced out of the ice lattice due to their low solubility in ice, and supersaturation of xylem sap as well as low water potential $(\Psi)$ are induced at the ice-liquid interface. Supersaturation of gases near the ice front may lead to bubble formation and potentially to cavitation and/or to burst of gases driven out from the branch. In this study, we investigated the origin and dynamics of freezing-related gas bursts and ultrasonic acoustic emissions (AEs), which are suggested to indicate cavitation. Picea abies and Salix caprea branch segments were exposed to frost cycles in a temperature test chamber, and $\mathrm{CO}_{2}$ efflux (indicating gas bursts) and AEs were recorded. On freezing, two-thirds of the observed gas bursts originated from the xylem and only one third from the bark. Simultaneously with gas bursts, AEs were detected. Branch $\Psi$ affected both gas bursts and AEs, with high gas burst in saturated and dry samples but relevant AEs only in the latter. Repeated frost cycles led to decreasing gas burst volumes and $\mathrm{AE}$ activity. Experiments revealed that the expanding ice front in freezing xylem was responsible for observed gas bursts and AEs, and that branch $\Psi$ influenced both processes. Results also indicated that gas bursts and cavitation are independently induced by ice formation, though both may be relevant for bubble dynamics during freezing. 


\section{Introduction}

Ice formation in wood is a complex dynamic process. At subzero temperatures, xylem sap can be in a doubly metastable state, when it is under tension and supercooled (Caupin et al. 2015). While increasing tension may induce cavitation, decreasing temperatures will lead to ice nucleation, after which ice will propagate longitudinally and radially within the xylem (Neuner et al. 2010, Pramsohler et al. 2012, Charrier et al. 2017). Freezing can damage plants at the cellular level by plasmolysis or intracellular ice formation, which is lethal for cells (Ristic \& Ashworth 1993, Pearce 2001, Ruelland et al. 2009, Charrier et al. 2013). Furthermore, frost cycles can cause embolism and, as a consequence, loss of xylem hydraulic conductivity (Tyree \& Sperry 1989, Sperry \& Sullivan 1992, Tyree et al. 1994, Mayr et al. 2007, Charrier et al. 2014). Following the classical theory of freeze-thaw-induced embolism, embolism occurs because gases, dissolved in unfrozen xylem sap, are hardly soluble in ice. During freezing, gases segregate and form bubbles within the ice (Sucoff 1969, Sperry \& Sullivan 1992, Mayr \& Sperry 2010, Sevanto et al. 2012, Charra-Vaskou et al. 2015). Upon thawing, these bubbles collapse and gases dissolve back into the sap. However, in the case of large bubbles and/or tension in the surrounding xylem sap, the bubbles can expand, fill the conduit, and lead to embolism (Pittermann \& Sperry 2006, Mayr \& Améglio 2016).

A visualization of bubble formation in freezing xylem sap has not yet been possible, but several studies reported ultrasonic acoustic emissions (AEs) to occur during ice formation (Raschi et al. 1989, Kikuta \& Richter 2003, Mayr et al. 2007, Mayr \& Zublasing 2010, Charrier et al. 2015). Under drought, AEs enable the detection of cavitation, i.e. the rapid tension release in the conduits when liquid water at low water potential $(\Psi)$ is replaced by water vapor near vacuum pressure (Tyree \& Dixon 1983, Salleo \& Lo Gullo 1986, Mayr \& Rosner 2011, Charrier 
et al. 2015). During freezing, the mechanism producing AEs is less clear, but previous studies indicated that AEs during freezing are caused by cavitation in the xylem sap due to low $\Psi$ at the ice-liquid interface (Mayr et al. 2007, Mayr \& Sperry 2010, Charrier et al. 2015, 2017). This suggests that there might be two embolism mechanisms involved in embolism formation of tree stems during frost cycles: the freeze-thaw-induced embolism (according to classical theory; Sucoff 1969, Sperry \& Sullivan 1992, Mayr \& Sperry 2010, Sevanto et al. 2012, CharraVaskou et al. 2015) and freeze-induced cavitation at the propagating ice front (producing AEs; Mayr et al. 2007, Mayr \& Sperry 2010, Charrier et al. 2015, 2017).

It was also shown that freezing can lead to emission of gases from xylem tissues-Lintunen et al. (2014) demonstrated for the first time, that gases were pushed out from conifer stems during ice propagation both in laboratory experiments and under field conditions. These results suggest that a proportion of gases dissolved in the xylem sap can be emitted from the xylem during freezing and is not trapped in ice. However, it is still unknown, from which tissue(s) the observed gas bursts originate and the underlying processes are not yet understood. It is likely that gas concentrations in front of the propagating ice front increase (Sevanto et al. 2012) and thus create a large concentration gradient between gases inside conduits and inter-conduit spaces (as well as ambient air). This gradient may accelerate the diffusion of gases out from the stem until the entire sap is frozen. In addition to this diffusion process, gases may be driven out from the vascular system by pressure-driven mass flow (Lintunen et al. 2014). The volume increase upon water-ice transition creates positive pressure (Robson \& Petty 1987), which will force gases to escape from the conduits much faster than by diffusion only. Theoretical calculations of gas volumes (Lintunen et al. 2014) suggest that bursts might reduce the likelihood of embolism formation during the freezing process by decreasing the sap gas content. 
In this study, we monitored the spatial and dynamic patterns of gas bursts and AEs of branches to analyze the effects of branch water status and the role of xylem and bark. Also, we studied potential links between gas bursts and AEs. Branch segments of Picea abies were exposed to frost cycles in a temperature test chamber, and gas bursts and AEs of saturated and dehydrated stems and peeled xylem as well as detached bark samples were measured. Measurements were also performed during repeated frost cycles, and additional freeze-thaw experiments on a broad-leaved species (Salix caprea). We hypothesized that (i) gas bursts (measured as $\mathrm{CO}_{2}$ efflux) originating from the xylem are larger than from the bark as proposed based on theoretical calculations by Lintunen et al. (2014); (ii) gas bursts and AEs occur simultaneously; and (iii) the volume of gas bursts and the number of AEs depend on branch $\Psi$, with the highest gas bursts and AEs recorded in medium dry samples. In fact, we expect freezing-induced cavitation to be absent in saturated samples, while in completely dehydrated samples, the remaining volume of the xylem sap should be too small for relevant gas bursts or AEs. Finally, (iv) repeated frost cycles were expected to cause a decrease in gas bursts and AEs as embolism formation would reduce the probability of cavitation and gas bursts would reduce sap gas concentrations in consecutive frost cycles. Based on this first simultaneous analyses of gas efflux (measured as $\mathrm{CO}_{2}$ efflux) and AEs, the identification of stem tissues producing the gas burst and the analysis of the influence of water potentials, this study should enable new insights into the complex process of freezing in plant xylem.

\section{Material and methods}

\subsection{Plant material}


Picea abies (L.) H. Karst. branches (1 to $1.5 \mathrm{~m}$ long) were collected from mature trees growing at Natters $\left(47^{\circ} 11^{\prime} \mathrm{N}, 11^{\circ} 12^{\prime} \mathrm{E}, 838 \mathrm{~m}\right.$ a.s.1.) near the Institute of Botany in Innsbruck, Austria. Sixteen branches were collected during the first week of March 2018 and the first 2 weeks of April 2018, before the start of the vegetation period. In addition, three branches of Salix caprea L. were collected during the second week of April at the alpine timberline (Praxmar, Tyrolean Central Alps, Austria; $47^{\circ} 09^{\prime} \mathrm{N}, 11^{\circ} 07^{\prime} \mathrm{E} ; 1680 \mathrm{~m}$ a.s.1.). P. abies and S. caprea species were selected as they are typical temperate/boreal species growing in extreme habitats, and thus are exposed to numerous frost cycles during winter.

Immediately after collection, branches were covered with black plastic bags and saturated in a bucket filled with tap water for at least $24 \mathrm{~h}$. After saturation, $\Psi$ was measured from $2-4$ end twigs $(\mathrm{ca} 10 \mathrm{~cm}$ ) per branch with a pressure chamber (PMS, model 1505D, Albany, NY, USA). A $10 \mathrm{~cm}$ long segment was cut under water from the base of each branch, and the remaining 35 cm long branch segment, without side branches, was further used for experiments (later referred to as sample). After cutting, the ends of the sample were immediately sealed with instant adhesive (Loctite 382 Instant Adhesive, Henkel, Düsseldorf, Germany) to minimize drying of the sample during the experiment.

\subsection{Ultrasonic acoustic emissions}

Ultrasonic AE measurements were performed with a PCI-8-based system (PAC Micro-II Express Digital AE System) and $150 \mathrm{kHz}$ resonance sensors (R15) connected to a preamplifier set to $40 \mathrm{~dB}$ (Physical Acoustics, Wolfegg, Germany). The threshold was set to $45 \mathrm{~dB}$ and the gain to $40 \mathrm{~dB}$ (Mayr et al. 2007, Mayr \& Rosner 2011, Charrier et al. 2015). With these settings, AEs can be detected over several centimeters in conifers. Registration and analysis of AEs were 
performed with AEwin software (Mistras Holdings Corp., Princeton, NJ, USA). Ultrasonic sensors were attached to both ends of the samples (Fig. 1). On stem samples, a small square (1 $\times 1 \mathrm{~cm}$ ) of the bark was removed to attach the sensors, and silicone grease was used to allow good contact between the sensors and the xylem surface.

\subsection{Gas exchange measurements}

A cuvette (outside length $10 \mathrm{~cm}$; inside length $5.5 \mathrm{~cm}$; diameter varied with branch size and mounting) made of transparent polyethylene plastic was wrapped around the central part of the sample, sealed at both ends with foam, and tightened with cable ties (Fig. 1). The joint of the cuvette was sealed with transparent tape. To allow constant air circulation, gas inlet and outlet tubes were connected to the cuvette and a battery-powered fan (1 lpm) was inserted into the cuvette (Fig. 1).

The gas exchange of the sample was measured with a mobile $\mathrm{CO}_{2}$ and $\mathrm{H}_{2} \mathrm{O}$ open-flow cuvette system that includes a high-resolution LI-840A gas analyzer (LI-COR, Lincoln, NE, USA). A Raspberry Pi computer was used to communicate with the gas analyzer, via an 8-channel transmitter (Nokeval, Nokia, Finland) and user-defined measuring protocols. The system was powered by a 48 Ah lead acid battery (Optima Batteries, WI, USA) and the measurement system was dynamic, such that it allowed supply air from a single source (ambient or cylinder air) to enter two cuvettes and a reference line (Fig. 2). Supply air was continuously passed through the cuvettes at a constant rate, and measurements were based on the concentration of the air stream flowing out of the cuvette and reference airline. The system was designed to measure three air samples in the following alternating order: air sample from the first cuvette,

171 air sample from the reference line (that fed substitute air for compensating the flush and sample 
172 flows from the cuvettes), and air sample from the second cuvette. The flows through the 173 cuvettes and reference lines were controlled via valves, which were turned on and off following 174 a measurement cycle. The flow rates for measurements and flushing during the supply air

175

176

177

178

179

180 measurement were set to $0.56 \mathrm{lpm}$.

\subsection{Freezing experiments}

To study $\mathrm{CO}_{2}$ bursts and AEs during freezing, we conducted freezing experiments in a temperature test chamber (Binder model MK 53, Tuttlingen, Germany). Gas exchange cuvettes and AE sensors were first installed onto samples. Further, two T-type thermocouples were positioned in the xylem located inside the cuvette with $2 \mathrm{~cm}$ distance from each other, and two thermocouples were positioned in the xylem located outside the cuvette (on both ends of the branch segment; see Fig. 1). Thermocouples allowed constant detection of xylem temperature and thus enabled to record when the xylem sap froze. Freezing releases thermal energy due to the phase change from water into ice (Burke et al. 1976) and, therefore, it is possible to detect sudden increases in local xylem temperature (i.e. freezing exotherm), which indicate freezing xylem sap. Xylem temperatures were measured at $10 \mathrm{~s}$ intervals and logged with a data logger (Campbell Scientific, Logan, UT, USA).

Samples were exposed to a temperature cycle inside the test chamber. The temperature was first set to $+2^{\circ} \mathrm{C}$ for $45 \mathrm{~min}$ before cooling for a period of $1 \mathrm{~h}$ to reach a temperature of $-8^{\circ} \mathrm{C}$. Then, the temperature was kept at $-8^{\circ} \mathrm{C}$ for $1 \mathrm{~h}$ before warming for $1 \mathrm{~h}$ to reach back $+2^{\circ} \mathrm{C}$. As last step, the temperature was kept constant at $+2^{\circ} \mathrm{C}$ for a minimum of 30 min (see Supporting Information). As with previous freezing studies, similar freezing/thawing rates were used to reduce the time needed for each experiment (Mayr et al. 2007, Mayr \& Sperry 2010, Lintunen 
et al. 2014). The temperature inside the gas exchange cuvette was always higher than in the surrounding test chamber but the temperature difference never exceeded $+3.5^{\circ} \mathrm{C}$. This was enabled by positioning the supply air tubing on the test chamber floor (loops with a total length of ca $2 \mathrm{~m}$ ) to allow heat transfer between the metallic test chamber and the tubing before it reached the cuvette. Drying of the samples during the experiments was expected to be small, because the cut ends of the branches were sealed and temperature of the test chamber decreased to $+2^{\circ} \mathrm{C}$ fast in the beginning of the experiment.

Based on these settings, several freezing experiments were conducted. In experiment 1, we tested for the origins of freezing-related $\mathrm{CO}_{2}$ bursts (xylem, bark, or both). The bark was carefully detached from three saturated $P$. abies samples as a single piece (i.e., bark samples included the phloem and outer bark). The detached bark was then positioned around a plastic tube and stabilized with small cable ties to prevent excess drying from the inner surface of the bark. Parallel to the detached bark sample, the peeled xylem sample was measured in the second cuvette. In experiment 2, we analyzed the influence of $\Psi$ on the $\mathrm{CO}_{2}$ bursts and AEs. After saturation, prior to exposure to the temperature cycles, $P$. abies samples were dehydrated to a $\Psi$ between $-3.2 \mathrm{MPa}$ and $-3.4 \mathrm{MPa}$ (hereafter called "dry"; 3 samples) and to a $\Psi$ below -4 MPa (hereafter called "very dry"; 3 samples). Four branches were kept saturated ( $\Psi$ between $-0.3 \mathrm{MPa}$ and $-0.5 \mathrm{MPa}$ ). In experiment 3, we studied the dynamics of $\mathrm{CO}_{2}$ bursts and AEs during three repeated frost cycles with four saturated $P$. abies samples. In other words, the same cycle (from $+2^{\circ} \mathrm{C}$ to $-8^{\circ} \mathrm{C}$ ) was repeated three times, and between cycles the temperature was kept for $1 \mathrm{~h}$ at $+2^{\circ} \mathrm{C}$. In experiment 4 , we studied $\mathrm{CO}_{2}$ bursts in three saturated samples of $S$. caprea $\mathrm{L}$. 
Freezing was artificially induced in all samples to decrease the variability of the freezing temperature and to control the point of ice nucleation. The tip of a copper nail, which was previously cooled via liquid nitrogen, was used to touch a $1 \times 2 \mathrm{~cm}$ debarked section of the branch (see also Fig. 1) at the sample base. Freezing was induced when the xylem temperature at the stem base (outside the cuvette) was around $-1.5^{\circ} \mathrm{C}$ in the saturated samples and around $3.0^{\circ} \mathrm{C}$ in the dehydrated samples to mimic their natural freezing temperatures (Lintunen et al. 2018). In experiment 3 , artificial freezing was induced at the stem base at $-1.5^{\circ} \mathrm{C}$ in the first two cycles, while freezing occurred spontaneously in the third cycle (due to the dehydrated surface of the debarked section, induction of freezing was not possible).

\subsection{Calculation of the freezing-related $\mathrm{CO}_{2} \underline{\text { burst and effective diffusion coefficient for } \mathrm{CO}_{2}}$}

The exchange of $\mathrm{CO}_{2}$ between the stem and its environment can be directly measured, while it is necessary to exclude respiration effects from the measured $\mathrm{CO}_{2}$ efflux to calculate the magnitude of the freezing-related $\mathrm{CO}_{2}$ burst. At above freezing temperatures, stem $\mathrm{CO}_{2}$ exchange and respiration are tightly coupled to each other, (albeit with a time lag; see Teskey \& McGuire 2007, Bloemen et al. 2013), while they are clearly decoupled during and after freezing. Very little information exists on the temperature dependence of the respiration rate in a frozen stems, therefore, we assumed similar temperature dependence before and after freezing (i.e., the temperature dependency of respiration was extrapolated to below freezing temperatures). The magnitude of the freezing-related $\mathrm{CO}_{2}$ burst is thus affected by $\mathrm{CO}_{2}$ produced by respiration (i.e., the concentration gradient between the inside and outside of the stem), the effective radial diffusion coefficient for $\mathrm{CO}_{2}$, and the partial pressure difference between the inside and outside of the stem. We used a previously published dynamic model of $\mathrm{CO}_{2}$ mass balance and transport within the stem (Hölttä \& Kolari 2009, Lintunen et al. 2014) 
to separate the freezing-related $\mathrm{CO}_{2}$ burst from the total stem $\mathrm{CO}_{2}$ efflux and to estimate the effective radial $\mathrm{CO}_{2}$ diffusion coefficient for the samples. The model (Hölttä \& Kolari 2009) solves the $\mathrm{CO}_{2}$ concentration profile within the stem by taking into account the $\mathrm{CO}_{2}$ produced in respiration, its partitioning between the liquid and gaseous phase, and its radial diffusion according to the concentration gradient within the stem. The change in the amount of $\mathrm{CO}_{2}$ $\left(\Delta N_{\mathrm{CO} 2}, \mu \mathrm{mol}\right)$ inside the stem during a time interval $\Delta \mathrm{t}(\mathrm{s})$ can be expressed as:

$\Delta N_{\mathrm{CO} 2} / \Delta \mathrm{t}=R\left(T_{\mathrm{xylem}}\right)-\left(C_{\mathrm{CO} 2}-C_{\mathrm{CO} 2, \mathrm{amb}}\right) d_{\mathrm{eff}}$

where $d_{\text {eff }}\left(\mathrm{m}^{3} \mathrm{~s}^{-1}\right)$ is an effective diffusion coefficient (Heitjans \& Kärger 2005, including information on size, geometry, and water content of the object, i.e., it is the constant of proportionality between the flux of $\mathrm{CO}_{2}$ due to diffusion and the difference in the concentration between the inside of the stem and the ambient air) and $R$ respiration rate $\left(\mu \mathrm{mol} \mathrm{s}{ }^{-1}\right), C_{\mathrm{CO} 2}$ is the $\mathrm{CO}_{2}$ concentration in the air phase inside the stem, and $C_{\mathrm{CO} \text {,amb }}$ is the ambient $\mathrm{CO}_{2}$ concentration inside the climate chamber. We modelled $R$ to be exponentially dependent on temperature inside the unfrozen stem $\left(T_{\mathrm{xylem}},{ }^{\circ} \mathrm{C}\right)$ : A Q10 value of 2.5 was used for the temperature dependency of respiration, similarly to the original parameterization. $R\left(T_{\mathrm{xylem}}\right)$ was fitted separately to each experiment based on the measurements before freezing. We assumed both gaseous (see Gartner et al. 2004) and liquid phases to account for $25 \%$ of stem volume. The relationship between $\mathrm{CO}_{2}$ concentration in gaseous and liquid phase was calculated by the Henry's law (Seinfeld \& Pandis 1998), which strongly depends on temperature. Model parameterization was kept as described in Lintunen et al. (2014).

The difference between the total measured $\mathrm{CO}_{2}$ efflux (which includes respired $\mathrm{CO}_{2}$ and freezing-related $\mathrm{CO}_{2}$ burst) and the modeled $\mathrm{CO}_{2}$ efflux (includes only respired $\mathrm{CO}_{2}$ ) represents 
the burst of $\mathrm{CO}_{2}$ released from the stem due to the freezing process. The volume of the freezingrelated $\mathrm{CO}_{2}$ burst was calculated as an integral of this difference from the moment of ice nucleation until the difference went to zero or the apoplastic water thawed at about $0^{\circ} \mathrm{C}$ (in some cases the burst was not over when the stem thawed). Values of the radial diffusion coefficient and absolute respiration were both fitted so that the dynamics and absolute values of the modeled $\mathrm{CO}_{2}$ efflux rate matched the measured $\mathrm{CO}_{2}$ efflux rate until the stem was frozen.

We also calculated the volume of freezing-related $\mathrm{CO}_{2}$ bursts normalized to the respiration rate of the sample at $+5^{\circ} \mathrm{C}$, (i.e., the volume of the burst was divided by the respiration efflux of the sample at $+5^{\circ} \mathrm{C}$; hereafter called "normalized $\mathrm{CO}_{2}$ burst"). In this way, samples with different respiration levels, and thus a different amount of stored $\mathrm{CO}_{2}$, could be compared.

\subsection{Statistical analysis}

Statistical analysis was performed with the GLM procedure in SAS ver. 9.4 (SAS Institute, Cary, NC, USA), which uses the method of least squares to fit general linear models. Analysis of variance was used to compare the volume of the freezing-related $\mathrm{CO}_{2}$ bursts, number of $\mathrm{AEs}$, respiration at $+5^{\circ} \mathrm{C}$, and effective diffusion coefficient of $\mathrm{CO}_{2}$ between samples of different $\Psi$, samples with peeled xylem, detached bark or both (i.e. intact branch), and samples of different species. In the analysis comparing samples with different $\Psi$, data were unbalanced due to different sample sizes between treatments. Therefore, a Type III test was used in GLM, because this test is independent of the number of observations per treatment combination. All tests were performed at a probability level of $5 \%$. Values are given as mean \pm standard error.

\section{Results}




\section{$\underline{\text { 3.1. Freezing-related } \mathrm{CO}_{2}} \underline{\text { bursts from peeled xylem and detached bark }}$}

298

299

In experiment 1 , freezing-related $\mathrm{CO}_{2}$ bursts were detected in both peeled xylem samples and detached bark samples of P. abies (Fig. 3A, B). In detached bark, the volume of absolute $\mathrm{CO}_{2}$ bursts was about 3.4-fold lower $(P=0.043)$ and the volume of normalized $\mathrm{CO}_{2}$ bursts about 7fold $(P=0.010)$ lower than that of intact samples (Fig. 4A). Neither the volume of absolute nor normalized $\mathrm{CO}_{2}$ bursts differed between peeled xylem and intact samples (Fig. 4A). $\mathrm{CO}_{2}$ efflux per surface area at $+5^{\circ} \mathrm{C}$ did not differ between detached bark, peeled xylem or intact samples (not shown). The effective $\mathrm{CO}_{2}$ diffusion coefficient was higher in detached bark than in peeled xylem or intact samples $(P<0.001)$, whereas there was no significant difference between peeled xylem and intact samples (Fig. 4A).

\section{2. $\mathrm{CO}_{2}$ efflux and acoustic emission dynamics at different water potential}

In experiment 2, samples showed decreasing $\mathrm{CO}_{2}$ efflux with decreasing xylem temperature until freezing occurred (Fig. 5A). The average level of $\mathrm{CO}_{2}$ efflux at $+5^{\circ} \mathrm{C}$ was $0.52 \pm 0.06$ $\mu \mathrm{mol} \mathrm{m} \mathrm{m}^{-2} \mathrm{~s}^{-1}$ and it decreased down to $0.30 \pm 0.03 \mu \mathrm{mol} \mathrm{m} \mathrm{m}^{-2} \mathrm{~s}^{-1}$ prior to freezing. $\mathrm{CO}_{2}$ efflux increased in all samples simultaneously with freezing, which was indicated by a freezing exotherm (Fig. 5A). The average maximum $\mathrm{CO}_{2}$ efflux during the freezing exotherm was 0.42 $\pm 0.03 \mu \mathrm{mol} \mathrm{m} \mathrm{m}^{-2} \mathrm{~s}^{-1}$. There was no statistical difference between saturated and dehydrated samples in the $\mathrm{CO}_{2}$ efflux at $+5^{\circ} \mathrm{C}$ or in the freezing-related $\mathrm{CO}_{2}$ bursts. However, the volume of the freezing-related normalized $\mathrm{CO}_{2}$ bursts in saturated and dry samples was 3.4-fold and 3.1-fold higher than in very dry samples, respectively (Fig. 6A). In contrast, the effective diffusion coefficient of $\mathrm{CO}_{2}$ was 6.9-fold and 2.9-fold higher in very dry samples than in 

from the analysis as an outlier). small.

saturated and dry samples, respectively (Fig. 6B, the sample with $\Psi$ of $-6.7 \mathrm{MPa}$ was dropped

Freezing-related $\mathrm{CO}_{2}$ bursts were not always completed before thawing. This was particularly obvious in saturated stems, which also showed long-lasting freezing exotherms. However, the $\mathrm{CO}_{2}$ efflux was always highest soon after the beginning of the exotherm and decreased toward the onset of thawing. Thus, the potential bias in the calculated burst volume is expected to be

Besides $\mathrm{CO}_{2}$ efflux, we also observed AEs during freezing (Fig. 5B). At the stem base (where ice nucleation was induced), the onset of AEs was always registered parallel to the start of the exotherm. AEs ceased when the exotherm peaked, until the temperature decreased again and new AEs were observed. The cumulative number of AEs was highest in samples with a $\Psi$ between $-2.5 \mathrm{MPa}$ and $-3.5 \mathrm{MPa}$ (Fig. 6C). At the stem apex (AE2 sensor in Fig. 1), the cumulative number of AEs was smaller than at the stem base and sometimes even missing. The onset of AEs was always later at the apex than at the stem base (Fig. 5B).

\section{$\underline{3.3 \mathrm{CO}_{2}}$ efflux and acoustic emission dynamics in subsequent frost cycles}

During three subsequent frost cycles (experiment 3), $\mathrm{CO}_{2}$ measurements indicated a pronounced freezing-related $\mathrm{CO}_{2}$ burst in the first cycle, a smaller one in the second, and a barely visible one in the third (Fig. 7). Unfortunately, the volume of the bursts could not be calculated due to difficulty in modeling respiration-induced $\mathrm{CO}_{2}$ efflux between the repeated frost cycles. Interestingly, $\mathrm{CO}_{2}$ efflux was also detected during thawing, whereby these thawing-induced bursts increased with consecutive temperature cycles. AEs, like in experiment 
2, were only observed during freezing, whereby the number of cumulative AEs was highest in the first cycle and decreased during consecutive cycles (Fig. 7).

\subsection{Comparing $\mathrm{CO}_{2}$ efflux and acoustic emission dynamics of Salix caprea}

Freezing-related $\mathrm{CO}_{2}$ bursts were also detected from saturated samples of $S$. caprea (Fig. 8A; experiment 4). The absolute volume of the bursts was not significantly different between species, but the volume of the normalized $\mathrm{CO}_{2}$ bursts with respiration rate at $+5^{\circ} \mathrm{C}$ was lower in $S$. caprea than in $P$. abies $(P=0.021$; Fig. 4B). This can be partly explained by the lower respiration rate of $P$. abies at $+5^{\circ} \mathrm{C}$ compared with that of $S$. caprea $(P<0.001)$ (Fig. 4B). Also, burst dynamics differed between species as the $\mathrm{CO}_{2}$ bursts started earlier (already at the time of ice nucleation outside the gas exchange cuvette) and were shorter in $S$. caprea than in $P$. abies (Fig. 8). The effective $\mathrm{CO}_{2}$ diffusion coefficient was clearly higher in $S$. caprea than in P. abies $(P=0.029$; Fig. 4B). The dynamics and patterns of AEs during freezing were similar to $P$. abies, with highest acoustic activity immediately after exotherm detection and a time lag between the two sensors (Fig. 8).

\section{Discussion} process in xylem, with respective complex dynamics and patterns in gas bursts and AEs. Our hypotheses were partly confirmed: (i) the majority of the $\mathrm{CO}_{2}$ efflux originated from the xylem; (ii) freezing-related gas bursts and AEs occurred simultaneously with freezing, indicating that the propagating ice front induced both; (iii) branch $\Psi$ had a major influence on both gas bursts and AEs, though the gas burst was high in saturated and medium dry samples, while relevant 
AEs were only observed in medium dry samples; and (iv) repeated frost cycles led to decreasing gas burst volumes and $\mathrm{AE}$ activity. In addition, $\mathrm{CO}_{2}$ bursts and AEs were demonstrated in $S$. caprea, which indicates that the observed processes are relevant in conifer as well as angiosperm species.

Experiment 1 demonstrated that about two thirds of released $\mathrm{CO}_{2}$ came from the xylem, while only one third originated from the bark, despite the high proportion of living tissues and large intercellular spaces in the latter. In a previous study on Pinus sylvestris and P. abies (Lintunen et al. 2014), a modeling approach suggested that the volume of freezing-related $\mathrm{CO}_{2}$ bursts corresponded to $70 \%$ of the total amount of dissolved $\mathrm{CO}_{2}$ in the xylem. When we now consider that one third of the gas burst originated from the bark, we can conclude that about $50 \%$ of the total $\mathrm{CO}_{2}$ within the xylem is released via a gas burst on freezing. It is important to note that xylem sap also contains other dissolved gases, with $\mathrm{N}_{2}$ and $\mathrm{O}_{2}$ representing the highest volumes. Analyzed $\mathrm{CO}_{2}$ burst dynamics, therefore, should be qualitatively equivalent to bursts of other gases but differ quantitatively due to differences in concentration in xylem sap and the ambient air, solubility and diffusion coefficients. The main source of $\mathrm{CO}_{2}$ within the bark was most likely within the intercellular spaces, which were filled with ice during freezing. This is because living cells in hardened $P$. abies stems avoid lethal intracellular ice formation by extracellular freezing (Sakai \& Okada 1971). The effective radial $\mathrm{CO}_{2}$ diffusion coefficient at $+5^{\circ} \mathrm{C}$ was clearly higher in the detached bark than in peeled xylem and intact samples, most likely due to the more porous bark tissue. The effective radial diffusion coefficient of $\mathrm{CO}_{2}$ has only rarely been measured for stems and varied between $10^{-11} \mathrm{~m}^{2} \mathrm{~s}^{-1}$ and $10^{-7} \mathrm{~m}^{2} \mathrm{~s}^{-1}$, depending on wood structure and water status (Sorz \& Hietz 2006, Spicer \& Holbrook 2007, Hölttä \& Kolari 2009). Our calculation of $10^{-9} \mathrm{~m}^{2} \mathrm{~s}^{-1}$ for P. abies stems (Fig. 4) falls well within this range. 
$\mathrm{CO}_{2}$ bursts were strongly influenced by the water status of the samples (experiment 2). The volume of normalized $\mathrm{CO}_{2}$ bursts detected during freezing was lower in dehydrated samples (Fig. 6; very dry) probably due to the following reasons. First, the sap volume (because of drought-induced embolism preceding frost treatment) and respective absolute volume of gases dissolved in the sap was low, and the volumetric increase upon water-ice transition was small. Second, a lower $\Psi$ causes lower freezing temperatures (Lintunen et al. 2018), which leads to higher ice propagation velocities (Kitaura 1967, Langer et al. 1978, Hacker \& Neuner 2007, Rauschenberger et al. 2013, Charrier et al. 2015). A low $\Psi$ is thus associated with small $\mathrm{CO}_{2}$ bursts because high ice propagation velocities may not leave enough time for the gases to diffuse out of the stem before being trapped in ice. Third, the effective radial diffusion coefficient of $\mathrm{CO}_{2}$ at $+5^{\circ} \mathrm{C}$ was negatively related to stem $\Psi$ (Fig. 6). This can be explained by the higher portion of air in dry stems as the diffusion of gases is about 10000 times faster in air than in water (Nobel, 2005). Diffusion of $\mathrm{CO}_{2}$ out of dry stems might lead to a low internal $\mathrm{CO}_{2}$ gas concentration prior to freezing and thus to small gas bursts on freezing. In very dry samples, the number of AEs was also small, probably because most conduits were already air-filled due to drought-induced embolism. In contrast, samples between -3.2 MPa and -3.4 MPa (Fig. 6; dry) showed a high number of AEs as well as pronounced gas bursts. Previous studies (Mayr et al. 2007, Mayr \& Sperry 2010, Charrier et al. 2015, 2017), indicated that AEs are induced by cavitation events near the moving ice front, causing a sudden release of tension. Mayr et al. (2007) clearly demonstrated that AEs during freezing are related to xylem water under tension as samples at critical water potential showed highest acoustic activity while saturated samples (or water in a straw) did hardly emit AEs. Charrier et al. (2015) found that AEs in freezing samples of several tree species showed two distinct phases: the first phase during ice nucleation and propagation, and the second after dissipation of the exothermal heat. They explained the first phase of AEs by low water potential of ice at the ice-liquid interface, which induced 
numerous and strong signals. This in accordance with our experiments, where the sensor near the point of artificial ice nucleation always recorded AEs earlier than the distal sensor (Fig. 3). Remarkably, the comparison of saturated and dry samples demonstrated that cavitation (indicated by AEs) and gas bursts, although both induced by ice formation, are not directly linked: gas bursts from dry samples were likely not solely related to cavitation events as saturated samples (Fig. 6; saturated) showed nearly identical, high $\mathrm{CO}_{2}$ effluxes.

Both freezing-related $\mathrm{CO}_{2}$ bursts and AEs were detected during each of the three consecutive frost cycles in experiment 3 (Fig. 7). However, the volume of the bursts and the number of AEs strongly decreased from the first to the third cycle. The number of AEs per freezing event has already been shown to decrease in a study by Mayr et al. (2007). The authors suggested that tracheids, which embolized during the first frost cycle, cannot cavitate a second time and thus the number of cavitating conduits (and respective AEs) decreases during subsequent frost cycles. $\mathrm{CO}_{2}$ bursts decreased during consecutive frost cycles because there was not probably enough time for the accumulation of new $\mathrm{CO}_{2}$ from tissue respiration in the xylem between the frost cycles to replace $\mathrm{CO}_{2}$ lost in the bursts. Also, embolized xylem portions may provide additional diffusion pathways out of the stem, which enable gas effluxes during thawing. Accordingly, $\mathrm{CO}_{2}$ bursts during thawing (also see Fig. 3) increased on each subsequent frost cycle. Further studies are required to disentangle the complex interrelations of processes during freezing and thawing, $\Psi$, and repeated frost cycles.

Freezing-induced gas bursts and AEs were also detected in S. caprea (Fig. 8), suggesting that simultaneous $\mathrm{CO}_{2}$ bursts and AEs are a phenomenon which can be found in many species. Interestingly, neither of our study species exhibited an increase in $\mathrm{CO}_{2}$ efflux before the freezing exotherm was observed. In contrast, Sperling et al. (2015) reported significant 
increases in stem respiration upon response to near-freezing temperatures in several woody species growing in temperate environments. The authors found that the increase in $\mathrm{CO}_{2}$ efflux before freezing was related to an acceleration of stem non-structural carbohydrate consumption. We did not observe an effect in $\mathrm{CO}_{2}$ efflux even when $P$. abies samples were kept near (but above) the freezing point for a longer time (data not shown) and thus it is unlikely that metabolic activity played a role in observed gas bursts. Our experiments also demonstrated that the majority of the $\mathrm{CO}_{2}$ efflux originated from xylem tissue (which mainly consists of dead conduit cells), and that the bursts occurred simultaneously with and not before ice nucleation. However, freezing-tolerant species growing at high elevation and/or latitudes differ in their temperaturedependent respiration patterns from temperate species, which might lead to interspecific differences in freezing-related $\mathrm{CO}_{2}$ burst dynamics and patterns.

\section{Conclusion}

Potential mechanisms underlying freezing-related patterns observed in the present study are summarized in Fig. 9: ice propagation forces gases out of the freezing sap, so they either form bubbles (which are then trapped in ice) or move away from the ice front and remain dissolved in the sap. In the latter case, the gas concentration in the remaining sap increases (Sevanto et al. 2012), thus increasing the driving force for gases to escape from the conduit via diffusion (leading to freezing-related gas burst). The detection of AEs during freezing indicates cavitation events (i.e., bubble formation) near the ice-liquid interface due to high tensions induced by ice (Mayr et al. 2007, Charrier et al. 2015). In this case, cavitation would result in a sudden release of tension inside the conduits and, consequently, in AEs. Accordingly, saturated samples show larger gas bursts as they contain larger gas volumes dissolved in the sap but emit only a few (or no) AEs as the tension in the sap is low (Fig. 9). In dry samples, higher tensions in the xylem 
471 lead to more AEs. Very dry samples contain a higher number of embolized conduits, which

472 contribute neither to gas bursts nor AEs.

473

474 Our study clearly indicates that processes occurring near the expanding ice front in freezing 475 xylem are responsible for observed gas burst and AE patterns. However, many aspects of the 476 freezing process in plant xylem (e.g., the small-scale spatial pattern of ice propagation, ice 477 formation through the pits, bubble formation) as well as the influence of environmental factors 478 (e.g., temperature gradients within xylem, growth conditions) and the relevance for plant life 479 exposed to freezing require further study.

\section{Conflict of interest}

482

The authors confirm that there are no conflicts of interest to declare.

\section{Funding}

This work was supported by the Academy of Finland (grants number 310375, 307331).

\section{Acknowledgements}

We thank technician Heikki Laakso for building the gas exchange measurement system used in this study, and technician Birgit Dämon for her technical help in the laboratory.

\section{Author contributions}


A. Lintunen, S. Mayr, and T. Hölttä planned, and A. Lintunen, A. Losso and S. Mayr conducted, the experiments. J. Aalto and T. Chan designed and built the gas measurement system together 498 with technician H. Laakso. T. Hölttä was responsible for the calculation of the freezing-related 499 burst and A. Lintunen for the statistical analysis. A. Lintunen had the main responsibility for 500 writing the paper, but all authors contributed to the writing process.

501

502 


\section{References}

Bloemen J, McGuire MA, Aubrey DP, Teskey RO, Steppe K (2013) Assimilation of xylemtransported $\mathrm{CO}_{2}$ is dependent on transpiration rate but is small relative to atmospheric fixation. J Exp Bot 64: 2129-2138.

Burke MJ, Gusta LV, Quamme HA, Weiser CJ, Li PH (1976) Freezing and injury in plants. Ann Rev Plant Physiol 27: 507-528.

Caupin F (2015) Escaping the no man's land: Recent experiments on metastable liquid water. Journal of Non-Crystalline Solids 407: 441-448.

Charra-Vaskou K, Badela E, Charrier G, Ponomarenko A, Bonhomme M, Foucat L, Mayr S, Améglio T (2015) Cavitation and water fluxes driven by ice water potential in Juglans regia during freeze-thaw cycles. J Exp Bot 67: 739-750.

Charrier G, Charra-Vaskou K, Kasuga J, Cochard H, Mayr S, Améglio T (2014) Freeze-thaw stress: effects of temperature on hydraulic conductivity and ultrasonic activity in ten woody angiosperms. Plant Physiol 164: 992-998.

Charrier G, Nolf M, Leitinger G, Charra-Vaskou K, Losso A, Tappeiner U, Améglio T, Mayr S (2017) Monitoring of freezing dynamics in trees: a simple phase shift causes complexity. Plant Physiol 173: 2196-2207. 
Charrier G, Poirier M, Bonhomme M, Lacointe A, Améglio T (2013) Frost acclimation in different organs of walnut trees Juglans regia L.: how to link physiology and modelling? Tree Physiol 33: 1229-1241.

Charrier G, Pramsohler M, Charra-Vaskou K, Saudreau M, Améglio T, Neuner G, Mayr S (2015) Ultrasonic emissions during ice nucleation and propagation in plant xylem. New Phytol 207: 570-578.

Gartner BL, Moore JR, Gardiner BA (2004) Gas in stems: abundance and potential consequences for tree biomechanics. Tree Physiol 24: 1239-1250.

Hacker J, Neuner G (2007) Ice propagation in plants visualized at the tissue level by infrared differential thermal analysis (IDTA). Tree Physiol 27: 1661-1670.

Heitjans P, Kärger J (2005) Diffusion in Condensed Matter. Heidelberg: Springer.

Hölttä T, Kolari P (2009) Interpretation of stem $\mathrm{CO}_{2}$ efflux measurements. Tree Physiol 29: 1447-1456.

Kikuta SB, Richter H (2003) Ultrasound acoustic emissions from freezing xylem. Plant Cell Environ 26: 383-388.

Kitaura K (1967) Supercooling and ice formation in Mulberry trees. In: Asahina E ed. Cellular injury and resistance in freezing organisms. Proceedings of international conference on low temperature science. Sapporo: Bunyeido Printing Co, 143-156. 
553

554

555

556

557

558

559

560

561

562

563

564

565

566

567

568

569

570

571

572 Mayr S, Sperry JS (2010) Freeze-thaw-induced embolism in Pinus contorta: centrifuge

573 experiments validate the 'thaw-expansion hypothesis' but conflict with ultrasonic emission

574

575

Langer JS, Sekerka RF, Fujioka T (1978) Evidence for a universal law of dendritic growth rates. J Cryst Growth 44: 414-418.

Lintunen A, Lindfors L, Kolari P, Juurola E, Nikinmaa E, Hölttä T (2014) Bursts of $\mathrm{CO}_{2}$ released during freezing offer a new perspective on avoidance of winter embolism in trees. Ann Bot 114: 1711-1718.

Lintunen A, Mayr S, Salmon Y, Cochard H, Hölttä T (2018) Drivers of apoplastic freezing in gymnosperm and angiosperm branches. Ecol Evol 8: 333-342.

Mayr S, Améglio T (2016) Freezing stress in tree xylem. In: Lüttge U, Cánovas F, Matyssek R, eds. Progress in Botany 77. Cham: Springer, 381-414.

Mayr S, Cochard H, Améglio T, Kikuta SB (2007) Embolism formation during freezing in the wood of Picea abies. Plant Physiol 143: 60-67.

Mayr S, Rosner S (2011) Cavitation in dehydrating xylem of Picea abies: energy properties of ultrasonic emissions reflect tracheid dimensions. Tree Physiol 31: 59-67. data. New Phytol 185: 1016-1024. 
576 Mayr S, Zublasing V (2010) Ultrasonic emissions from conifer xylem exposed to repeated

577 freezing. J Plant Physiol 167: 34-40.

578

579 Neuner G, Xu B, Hacker J (2010) Velocity and pattern of ice propagation and deep

580 supercooling in woody stems of Castanea sativa, Morus nigra and Quercus robur measured

581 by IDTA. Tree Physiol 30: 1037-1045.

582

583 Nobel PS (2005) Physiochemical and environmental plant physiology. New York: WH

584 Freeman and Company.

585

586 Pearce RS (2001) Plant freezing and damage. Ann Bot 87: 417-424.

587

588

589

Pittermann J, Sperry JS (2006) Analysis of freeze-thaw embolism in conifers. The interaction between cavitation pressure and tracheid size. Plant Physiol 140: 374-382.

590

591

Pramsohler M, Hacker J, Neuner G. 2012. Freezing pattern and frost-killing temperature of

592 apple (Malus domestica) wood under controlled conditions and in nature. Tree Physiol 32:

593 819-828.

594

595 Raschi A, Scarascia Mugnozza G, Surace R, Valentini R, Vazzana C (1989) The use of 596 ultrasound technique to monitor freezing and thawing of water in plants. Agr Ecosyst Environ $597 \quad 27: 411-418$.

598 
599

600

601

602

603

604

605

606

607

608

609

610

611

612

613

614

615

616

617

618

619

620

621

622

623

Rauschenberger P, Criscione A, Eisenschmidt K, Kintea D, Jarkilić S, Tuković Z, Roisman

IV, Weigand B, Tropea C (2013) Comparative assessment of volume-of- fluid and level-set methods by relevance to dendritic ice growth in supercooled water. Comp Fluids 79: 44-52.

Ristic Z, Ashworth EN (1993) Ultrastructural evidence that intracellular ice formation and possibly cavitation are the sources of freezing injury of supercooling wood tissue of Cornus florida L. Plant Physiol 103: 753-761.

Robson DJ, Petty JA (1987) Freezing in conifer xylem I. Pressure changes and growth velocity of ice. J Exp Bot 38: 1901-1908.

Ruelland E, Vaultier MN, Zachowski A, Hurry V (2009) Cold signaling and cold acclimation in plants. Adv Bot Res 49: 35-150.

Sakai A, Okada S (1971) Freezing resistance of conifers. Silvae Genetica 20: 91-97.

Salleo S, Lo Gullo MA (1986) Xylem cavitation in nodes and internodes of whole Chorisia insignis H. B. et K. plants subjected to water stress. Relations between xylem conduit size and cavitation. Ann Bot 58: 431-441.

Seinfeld JH, Pandis SN (1998) Atmospheric chemistry and physics: from air pollution to climate change. New York: Wiley \& Sons.

Sevanto S, Holbrook NM, Ball M (2012) Freeze/thaw-induced embolism: probability of critical bubble formation depends on speed of ice formation. Front Plant Sci 3: 107. 
Sorz J, Hietz P (2006) Gas diffusion through wood: implications for oxygen supply. Trees 20: $34-41$.

627

628

629

630

631

632

633

634

635

636

637

638

639

640

641

642

643

644

645

646

647

Sperling O, Earles JM, Secchi F, Godfrey J, Zwieniecki MA (2015) Frost induces respiration and accelerates carbon depletion in trees. PLOS ONE, doi:

https://doi.org/10.1371/journal.pone.0144124

Sperry JS, Sullivan JEM (1992) Xylem embolism in response to freeze-thaw cycles and water stress in ring-porous, diffuse-porous and conifer species. Plant Physiol 100: 605-613.

Spicer R, Holbrook NM (2007) Effects of carbon dioxide and oxygen on sapwood respiration in five temperate tree species. J Exp Bot 58: 1313-1320.

Sucoff E (1969) Freezing of conifer xylem and the cohesion-tension theory. Physiol Plantarum 22: 424-431.

Teskey RO, McGuire MA (2007) Measurement of stem respiration of sycamore (Platanus occidentalis L.) trees involves internal and external fluxes of $\mathrm{CO}_{2}$ and possible transport of $\mathrm{CO}_{2}$ from roots. Plant Cell Environ 30: 570-579.

Tyree MT, Davis SD, Cochard H (1994) Biophysical perspectives of xylem evolution: is there a tradeoff of hydraulic efficiency for vulnerability to dysfunction? IAWA J 15: 335-360. 
648 Tyree MT, Dixon MA (1983) Cavitation events in Thuja occidentalis L.? Ultrasonic acoustic

649 emissions from the sapwood can be measured. Plant Physiol 72: 1094-1099.

650

651 Tyree MT, Sperry JS (1989) Vulnerability of xylem to cavitation and embolism. Annu Rev

652 Plant Physiol Plant Mol Biol 40: 19-38.

653 


\section{Figure legends}

Figure 1. Cuvette and measurement setup. Both ends of the branch segment (brown) were sealed with glue (light blue) and a transparent cuvette was wrapped around the central part of the sample. The cuvette was sealed at both ends with foam (black), and gas inlet and outlet tubes (dark blue) were connected to the cuvette. To allow constant air circulation, a battery-powered mini fan $(1 \mathrm{lpm})$ was inserted. The system for measuring gas exchange is presented in Fig. 2. Two acoustic emission (AE) sensors and two thermocouples (T) were attached to both sides of the cuvette- $\mathrm{AE} 1$ and $\mathrm{T} 1$ at the base and AE2 and T4 at the apex. Two thermocouples were also inserted inside the cuvette- $-\mathrm{T} 2$ at the base and T3 at the apex. A small square $(1 \times 2 \mathrm{~cm})$ of the bark was removed at the stem base to enable artificial freezing.

Figure 2. Schematic diagram of the gas exchange measurement system for simultaneous measurements of two samples. Circles with an internal triangle represent the pumps, and S0, S1, S2, F1, and F2 are the valves. MFM refers to Mass Flow Meter. Because of using pressurized air from a cylinder, the pump and buffer for the supply air were bypassed (shown with a dashed line). The measurement consists of a stepwise program that is repeated: i) both cuvettes are first flushed with supply air for $30 \mathrm{~s}$ and the supply air concentration is measured during the flushing. ii) The supply air line for cuvette 1 is closed and the concentration in the cuvette is measured for $60 \mathrm{~s}$; meanwhile, cuvette 2 continues to be flushed with supply air. iii) Both cuvettes are again flushed with supply air for 30s, and the supply air concentration is measured during the flushing. iv) The supply air line for cuvette 2 is closed and the concentration in the cuvette is measured for 60s; meanwhile, cuvette 1 continues to be flushed with supply air. Figure 1 shows how the cuvette was mounted on the sample. 
679 Figure 3. Time series of a measured $\mathrm{CO}_{2}$ efflux and a modeled respiratory $\mathrm{CO}_{2}$ release from a

680

681

682

683

684

685

686

687

688

689

690

691

692

693

694

695

696

697

698

699

700

701

702

703

peeled Picea abies sample (A) and detached bark (B). At the beginning of the experiment, the sample water potential was $-1.5 \mathrm{MPa}$. Xylem temperatures inside the cuvette are shown (T2 and T3). The background color represents the frozen (white) and thawed (light gray) periods of the xylem sap.

Figure 4. A) Comparison of the average volume of freezing-related $\mathrm{CO}_{2}$ bursts, freezing-related $\mathrm{CO}_{2}$ bursts normalized with respiration efflux at $+5^{\circ} \mathrm{C}$, and the effective $\mathrm{CO}_{2}$ diffusion coefficient for peeled xylem, detached bark, and intact samples (i.e. samples including both xylem and phloem) of saturated Picea abies. There was no difference between peeled xylem, detached bark, and intact samples in the respiration efflux at $+5^{\circ} \mathrm{C}$. B) Comparison of the average volume of freezing-related $\mathrm{CO}_{2}$ bursts, normalized $\mathrm{CO}_{2}$ bursts, and respiration efflux at $+5^{\circ} \mathrm{C}$ between saturated samples of $P$. abies and Salix caprea. There was no difference between species in the effective $\mathrm{CO}_{2}$ diffusion coefficient. Significant differences $(P<0.05)$ between groups are indicated by different letters and roman numbers. Mean \pm standard error.

Figure 5. Time series of a measured $\mathrm{CO}_{2}$ efflux and a modeled respiratory $\mathrm{CO}_{2}$ release (A) and acoustic emissions (AEs) (B) measured on a P. abies sample dehydrated to $-3.4 \mathrm{MPa}$. Xylem temperatures inside the cuvette (T2 and T3) are shown in A, whereas xylem temperatures outside the cuvette (T1 and T4) are shown in B. The background color represents the frozen (white) and thawed (light gray) periods of the xylem sap.

Figure 6. Comparison of the volume of freezing-related $\mathrm{CO}_{2}$ bursts normalized with respiration at $+5^{\circ} \mathrm{C}(\mathrm{A})$, effective diffusion coefficient of $\mathrm{CO}_{2}(\mathrm{~B})$, and total number of acoustic emissions (AEs) during the freezing exotherm measured at the stem base (C) for four saturated samples 
(water potential, $\Psi$, between $-0.3 \mathrm{MPa}$ and $-0.5 \mathrm{MPa}$ ), three dry samples ( $\Psi$ between $-3.2 \mathrm{MPa}$

705

706

707

708

709

710

711

712

713

714

715

716

717

718

719

720

and $-3.4 \mathrm{MPa})$ and three very dry samples ( $\Psi$ lower than $-4 \mathrm{MPa})$. Significant differences $(P$ $<0.05$ ) between groups are indicated by different letters. Mean \pm standard error.

Figure 7. Time series of $\mathrm{CO}_{2}$ efflux and acoustic emissions (AEs; see also Fig. 1) from a Picea abies sample during three subsequent frost cycles. At the beginning of the experiment, sample water potential was $-0.8 \mathrm{MPa}$. The background color represents the frozen (white) and thawed (light gray) periods of the xylem sap, white arrows show freezing-related $\mathrm{CO}_{2}$ bursts, and gray arrows show thawing-induced $\mathrm{CO}_{2}$ bursts.

Figure 8. Time series of $\mathrm{CO}_{2}$ efflux and modeled respiratory $\mathrm{CO}_{2}$ release $(\mathrm{A})$ and cumulative number of acoustic emissions (AEs) (B) from a Salix caprea sample. At the beginning of the experiment, sample water potential was $-0.3 \mathrm{MPa}$. Xylem temperatures inside the cuvette is shown in A (T2 and T3), whereas xylem temperature outside the cuvette in sample base (T1) and top (T4) is shown in B. The background color represents the frozen (white) and thawed (light gray) periods of the xylem sap.

Figure 9. Schematic of freezing in xylem and underlying processes of gas bursts and acoustic emissions (AEs) during ice propagation. The schematic is presented separately for a saturated (A), dry (B) and a very dry branch (C).

(1)

(1)

(1)

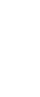
(1) 


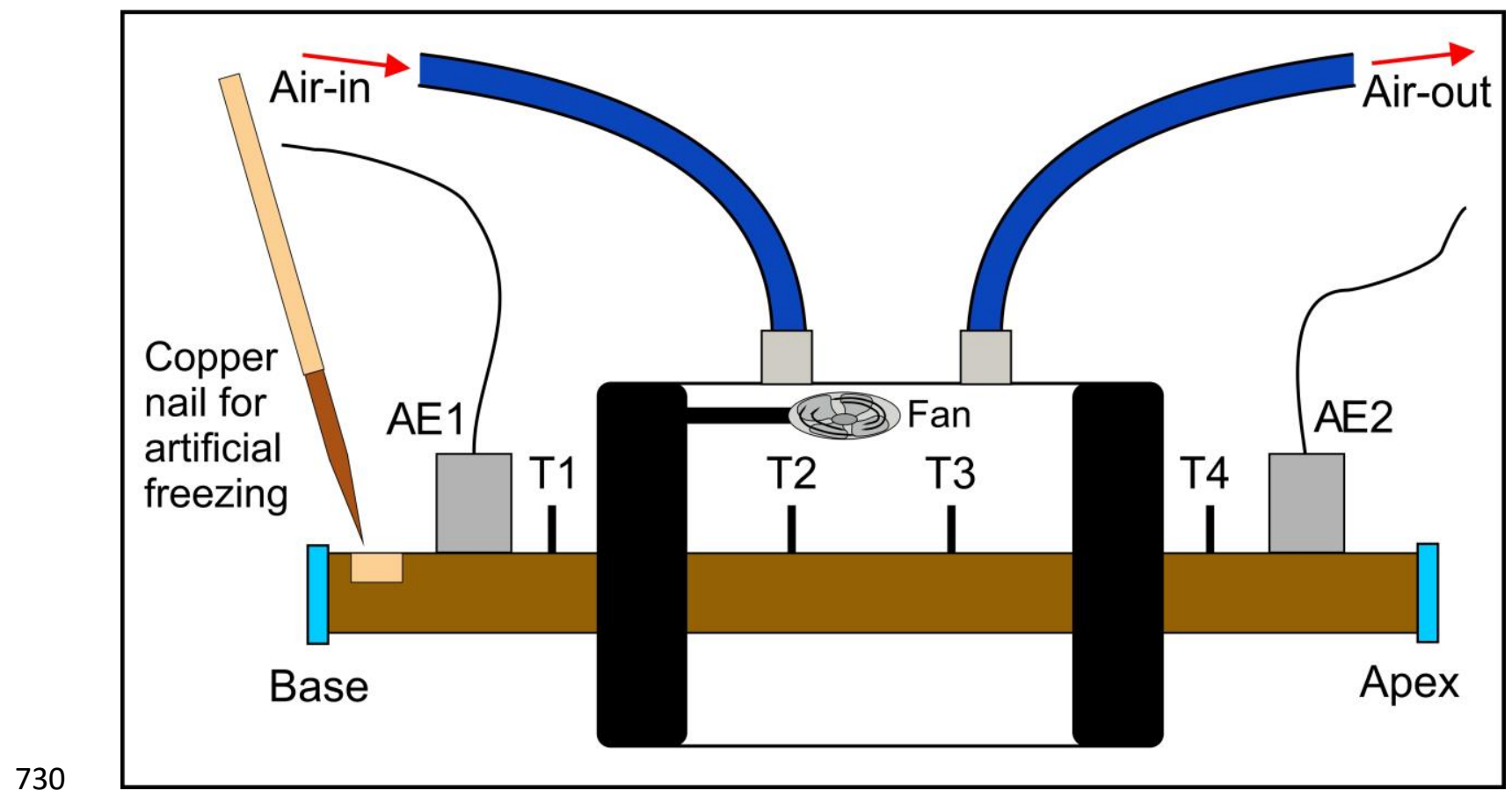

$731 \quad$ Fig. 1

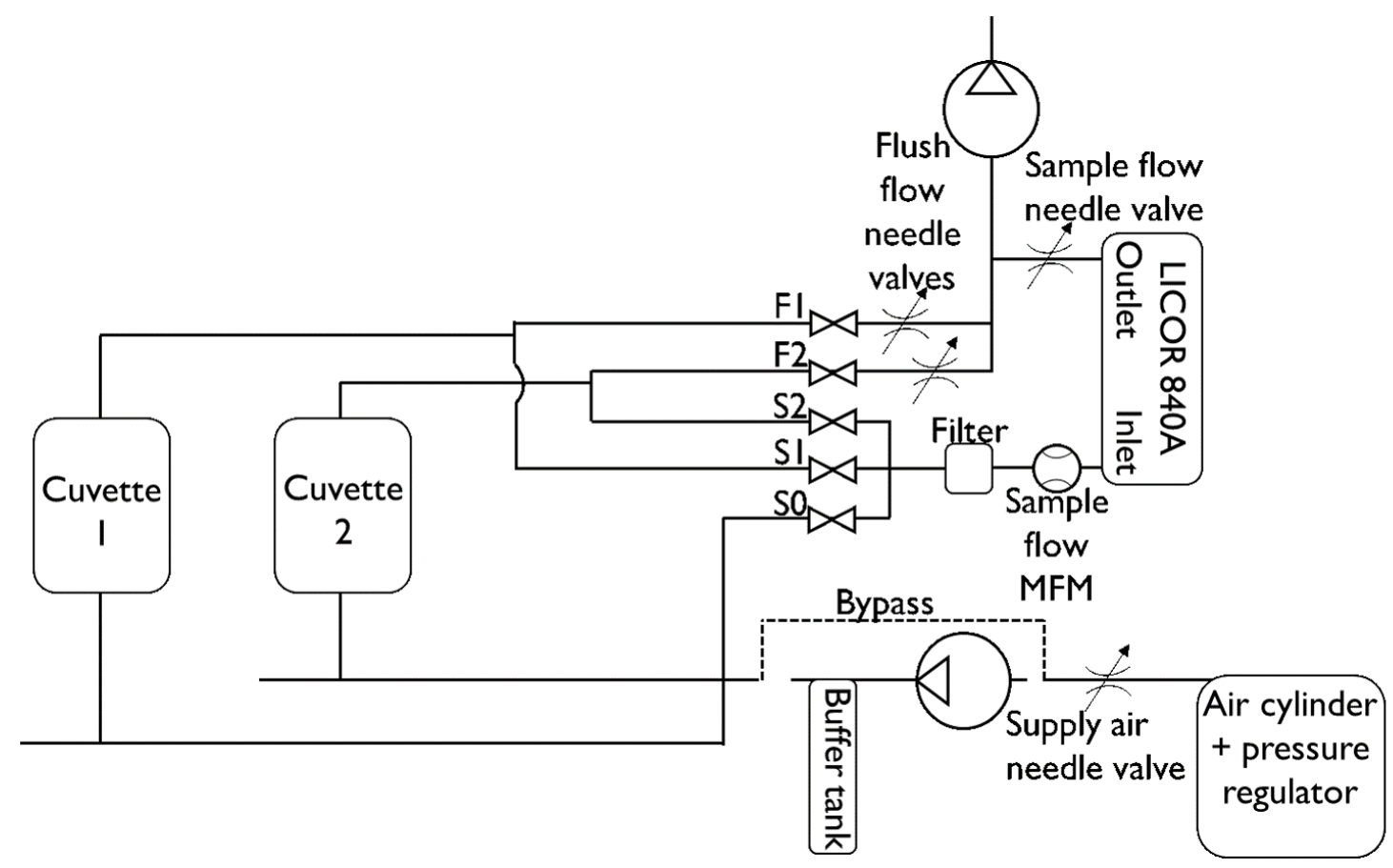

732

$733 \quad$ Fig. 2 

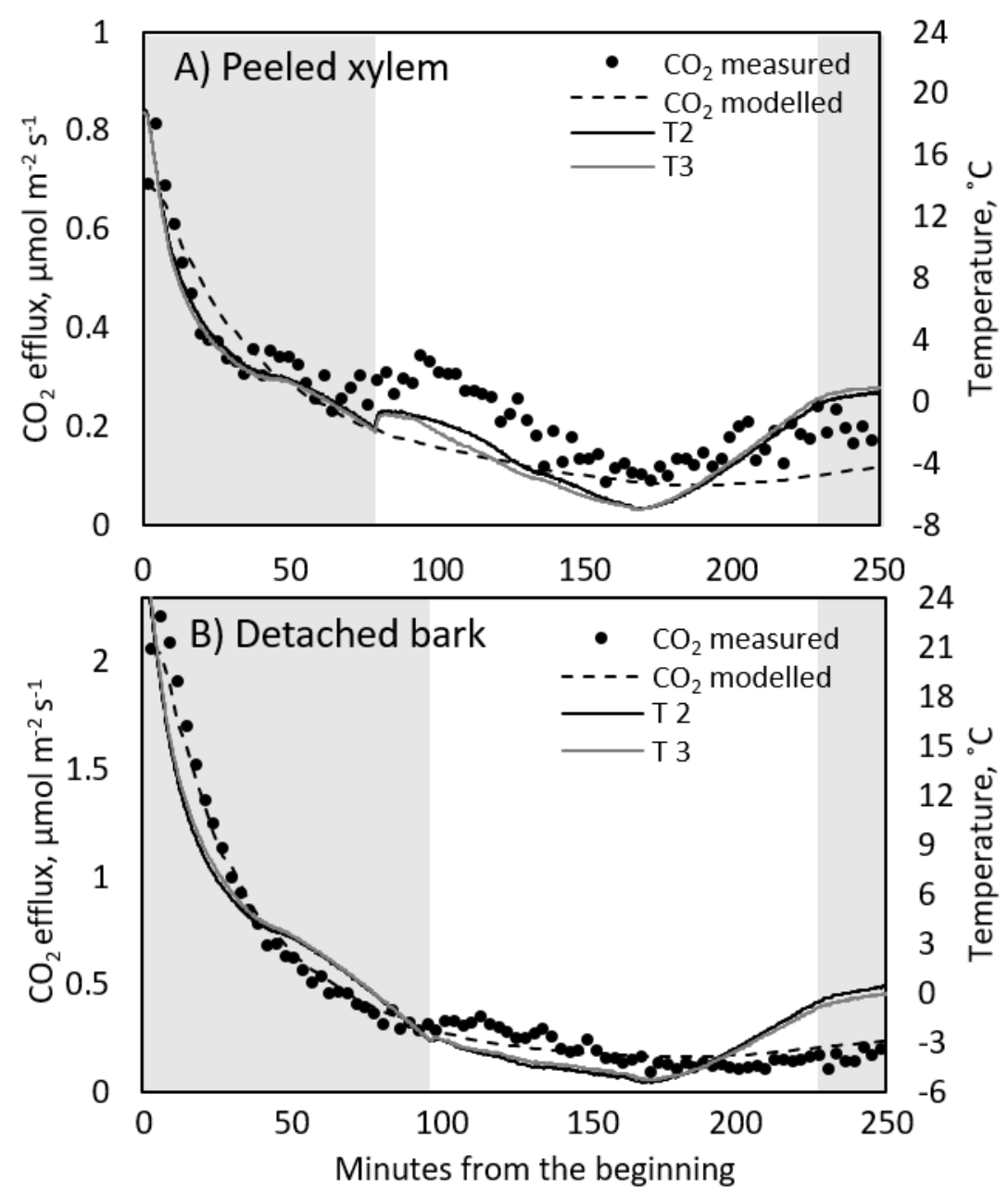

734

$735 \quad$ Fig. 3 

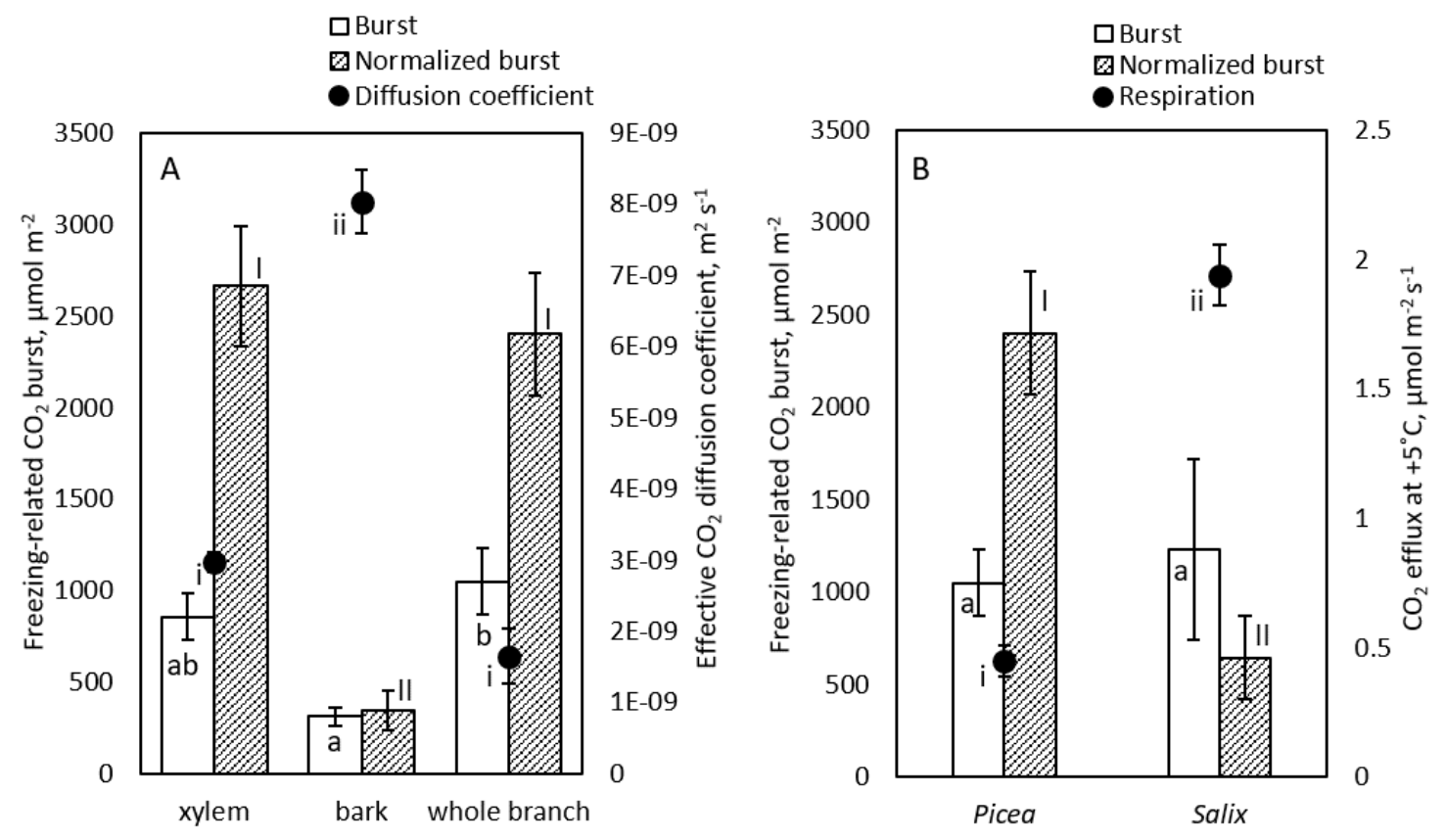

736

$737 \quad$ Fig. 4 

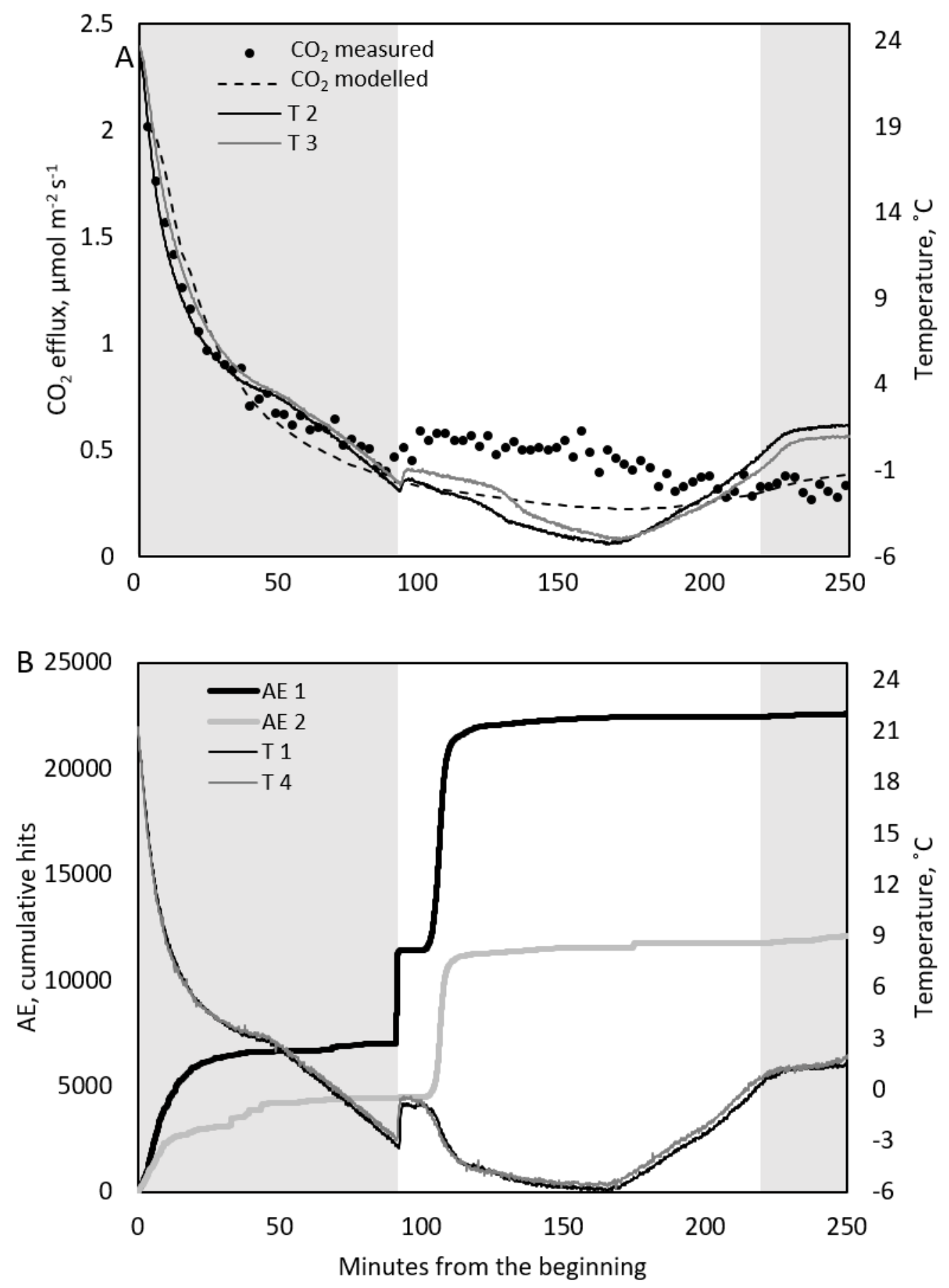

738

Fig. 5 

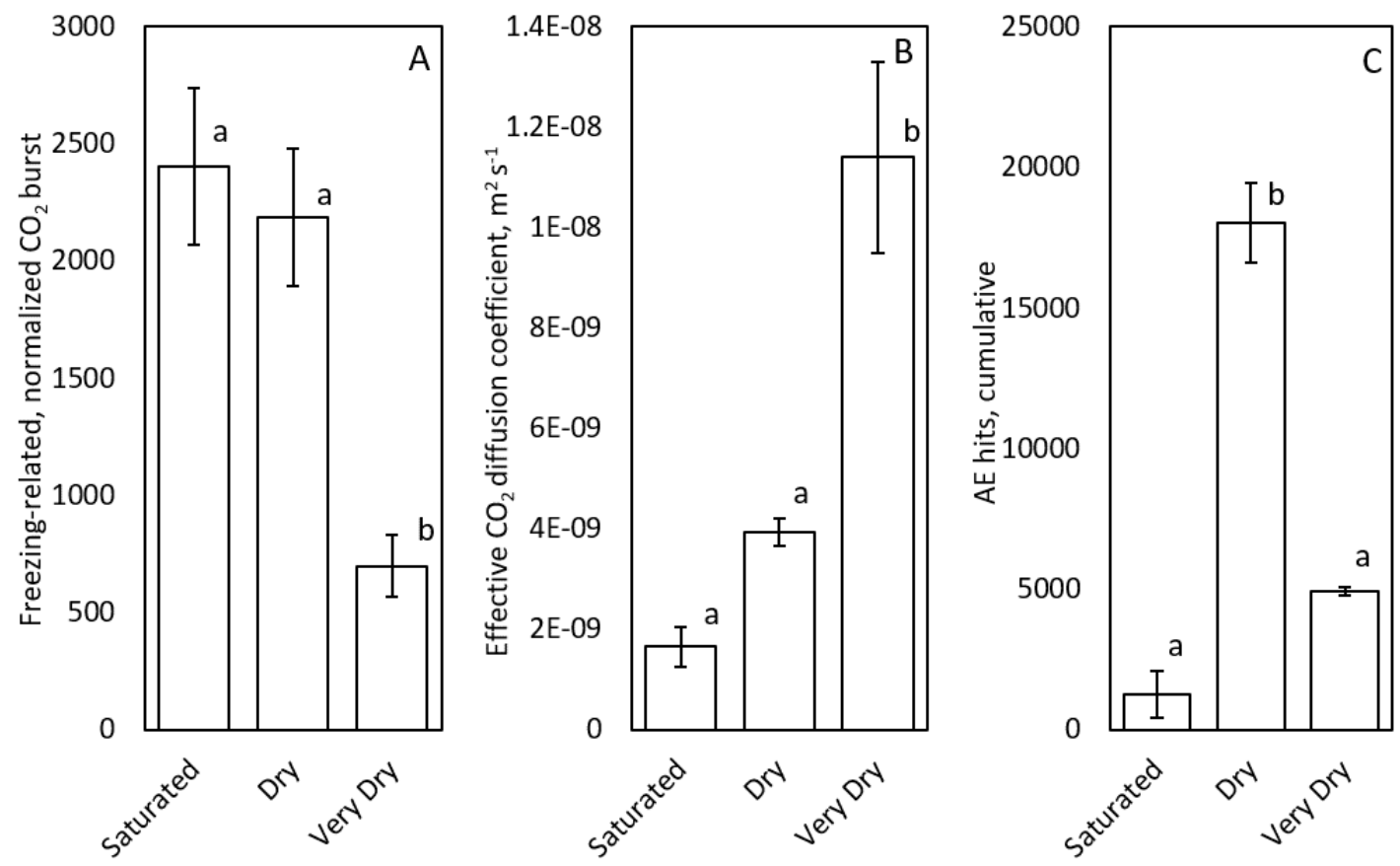

740

741

Fig. 6

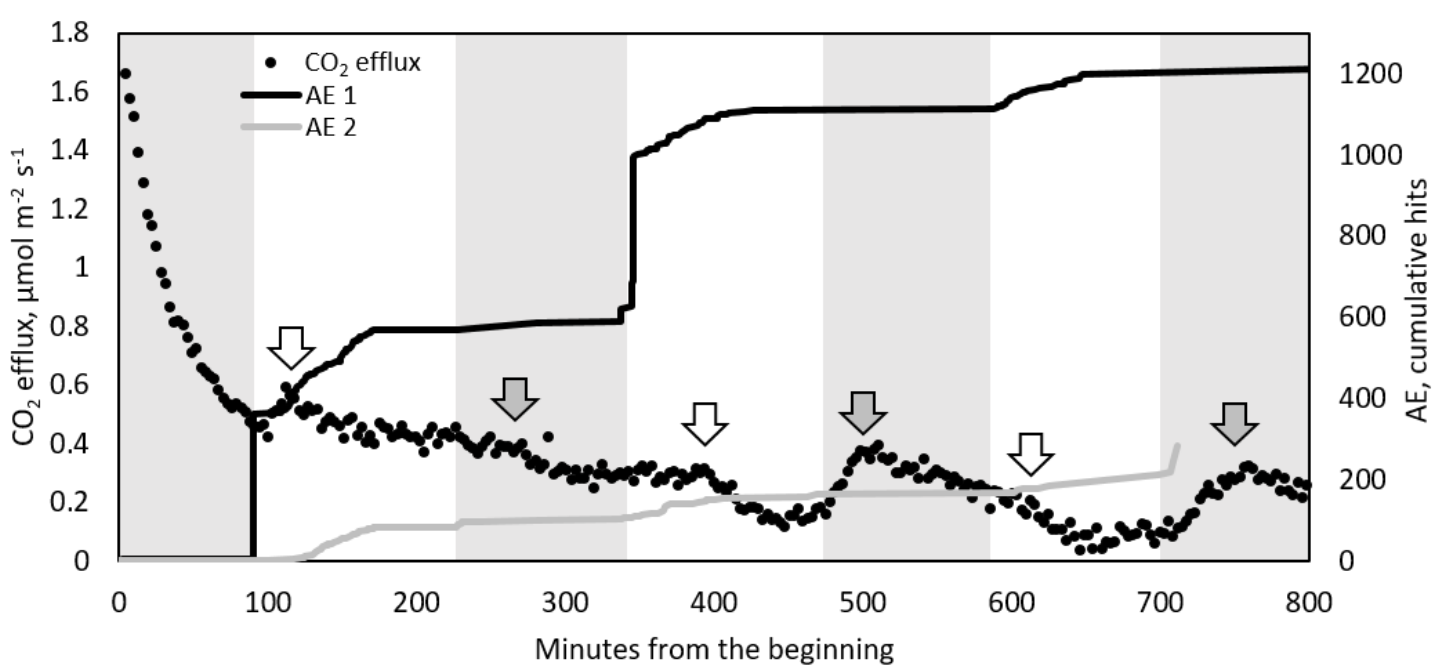

$743 \quad$ Fig. 7 

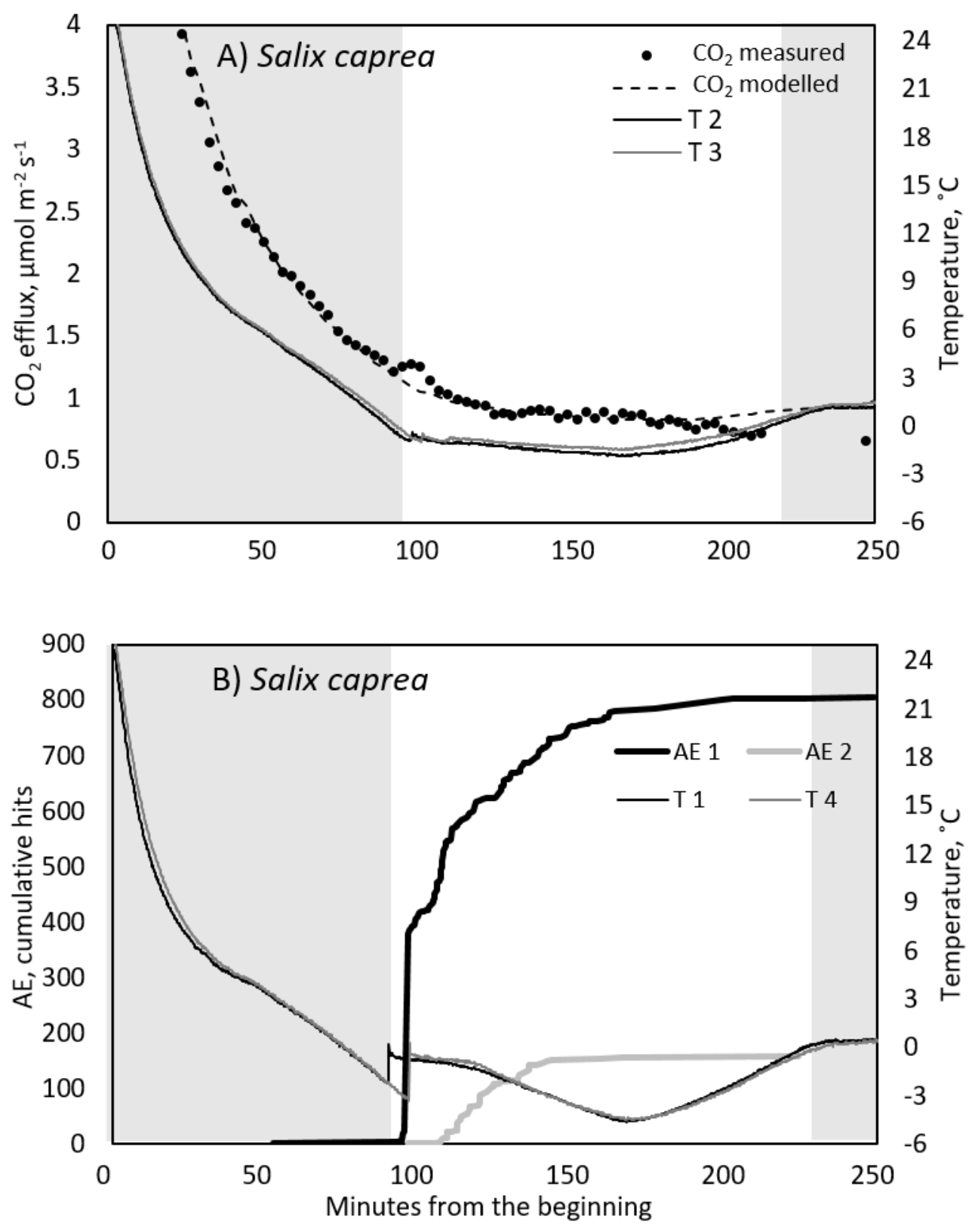

Fig. 8 


\section{A. Saturated}

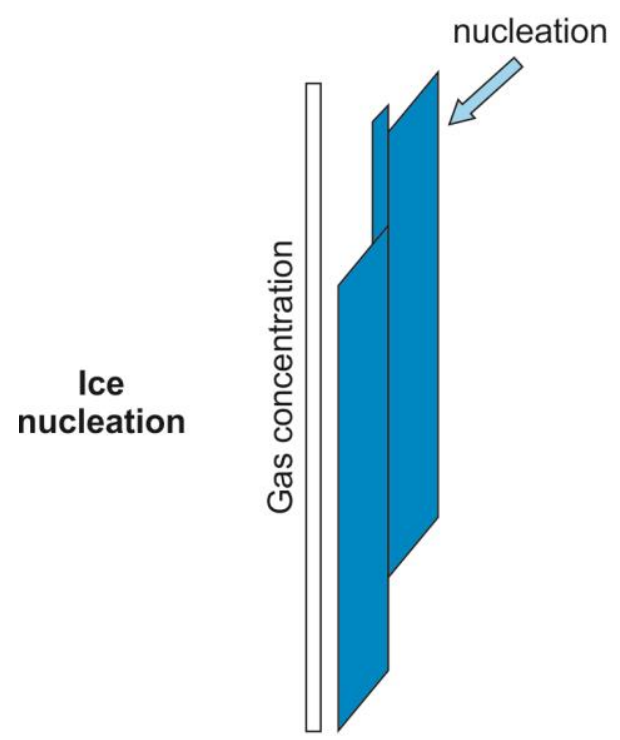

Ice propagation

746

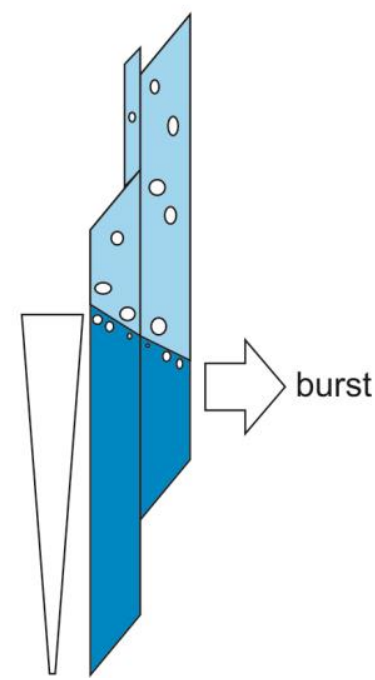

B. Medium dry
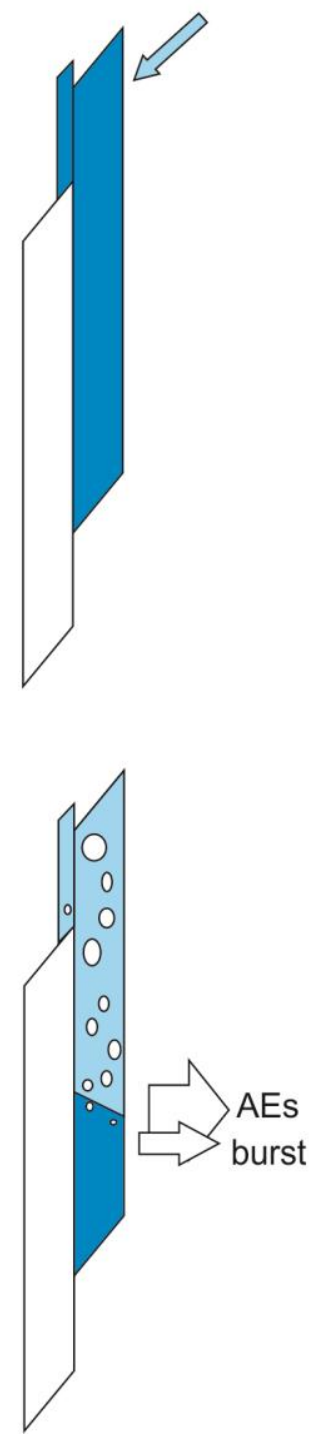

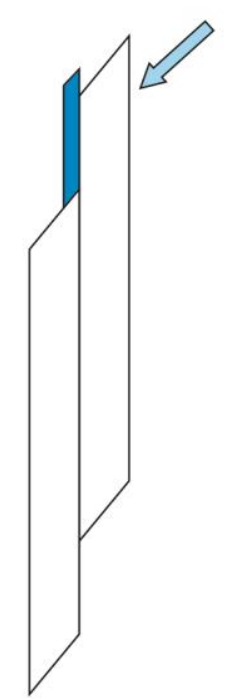

C. Dehydrated

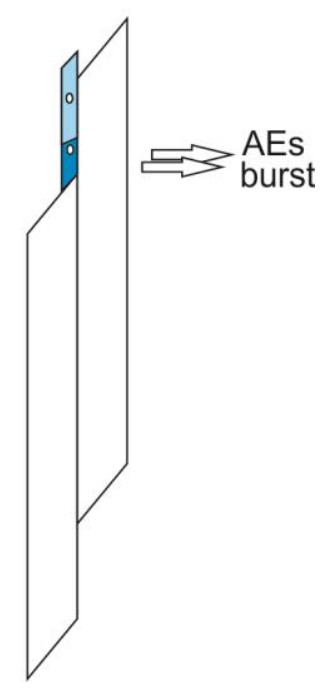

Fig. 9 